\title{
Dolphin Morbillivirus and Toxoplasma gondii coinfection in a Mediterranean fin whale (Balaenoptera physalus)
}

\author{
Sandro Mazzariol ${ }^{1 *}$, Federica Marcer², Walter Mignone ${ }^{3}$, Laura Serracca ${ }^{3}$, Mariella Goria ${ }^{3}$, Letizia Marsili,
} Giovanni Di Guardo ${ }^{5}$ and Cristina Casalone ${ }^{3}$

\begin{abstract}
Background: Although Morbillivirus and Toxoplasma gondii have emerged as important pathogens for several cetaceans populations over the last 20 years, they have never been identified together in a Mysticete. In particular, morbilliviral infection has been never described in the Mediterranean fin whale population.

Case presentation: On January 2011 an adult male of fin whale (Balaenoptera physalus) stranded along the Tyrrhenian coastline of Italy. During necropsy, tissue samples from heart, skeletal muscle, mesenteric lymph nodes, liver, spleen, lung, and kidney were collected and subsequently analyzed for Morbillivirus and Toxoplasma gondii by microscopic and molecular methods. Following the detailed necropsy carried out on this whale, molecular analysis revealed, for the first time, the simultaneous presence of a Dolphin Morbillivirus (DMV) and T. gondii infection coexisting with each other, along with high organochlorine pollutant concentrations, with special reference to DDT.

Conclusion: This report, besides confirming the possibility for Mysticetes to be infected with DMV, highlights the risk of toxoplasmosis in sea water for mammals, already immunodepressed by concurrent factors as infections and environmental contaminants.
\end{abstract}

Keywords: Dolphin Morbillivirus, Toxoplasma gondii, Fin whale, DDT, Mediterranean Sea

\section{Background}

Among the several threats to which free-ranging cetaceans are exposed, Morbillivirus and Toxoplasma gondii are believed to represent a serious hazard to their health and conservation [1]. Nevertheless, morbilliviral infections have been rarely described in mysticetes [2-4], while $T$. gondii has been also reported as a disease-causing protozoan agent in immunocompromised Odontocetes $[5,6]$ affected by a severe meningo-encephalitis, as recently documented in the Mediterranean striped dolphin (Stenella coeruleoalba) population [7].

\section{Case presentation}

An adult male fin whale (Balaenoptera physalus) was found stranded dead (length: $16.7 \mathrm{~m}$; estimated weight:

\footnotetext{
* Correspondence: sandro.mazzariol@unipd.it

'Department of Comparative Biomedicine and Food Science, University of

Padova, AGRIPOLIS - Viale dell'Università, 16, 35020 Legnaro, (PD), Italy

Full list of author information is available at the end of the article
}

$25,000 \mathrm{~kg}$ ) on January 25, 2011 (Figure 1A). Using a photo-identification method, the animal matched with one whale that was observed swimming slowly in shallow waters, in front of the coast of Tuscany (Tyrrhenian Sea), Italy, close to the cost of Follonica (GR) on January 16,2011 , as well as in front of the tourist port of Viareggio (PI) on January $23,80 \mathrm{~km}$ north of the first sighting area. A detailed post-mortem examination was performed on site $\left(43^{\circ} 44^{\prime} 42^{\prime \prime} \mathrm{N}, 10^{\circ} 16^{\prime} 35^{\prime \prime} \mathrm{E}\right)$ within $24 \mathrm{~h}$ after stranding, following specific necropsy protocols developed for large whales $[8,9]$. Sampled tissues were preserved in $10 \%$ neutral buffered formalin for histopathology, refrigerated for microbiology and parasitology, and frozen for biomolecular and ecotoxicological investigations. For histopathology, tissues were paraffinembedded, sectioned at $4 \mu \mathrm{m}$, and routinely stained with hematoxylin and eosin (HE). Selected tissue sections from the main organs were also stained by different histochemical techniques (PAS, Prussian blue,

\section{() Biomed Central}




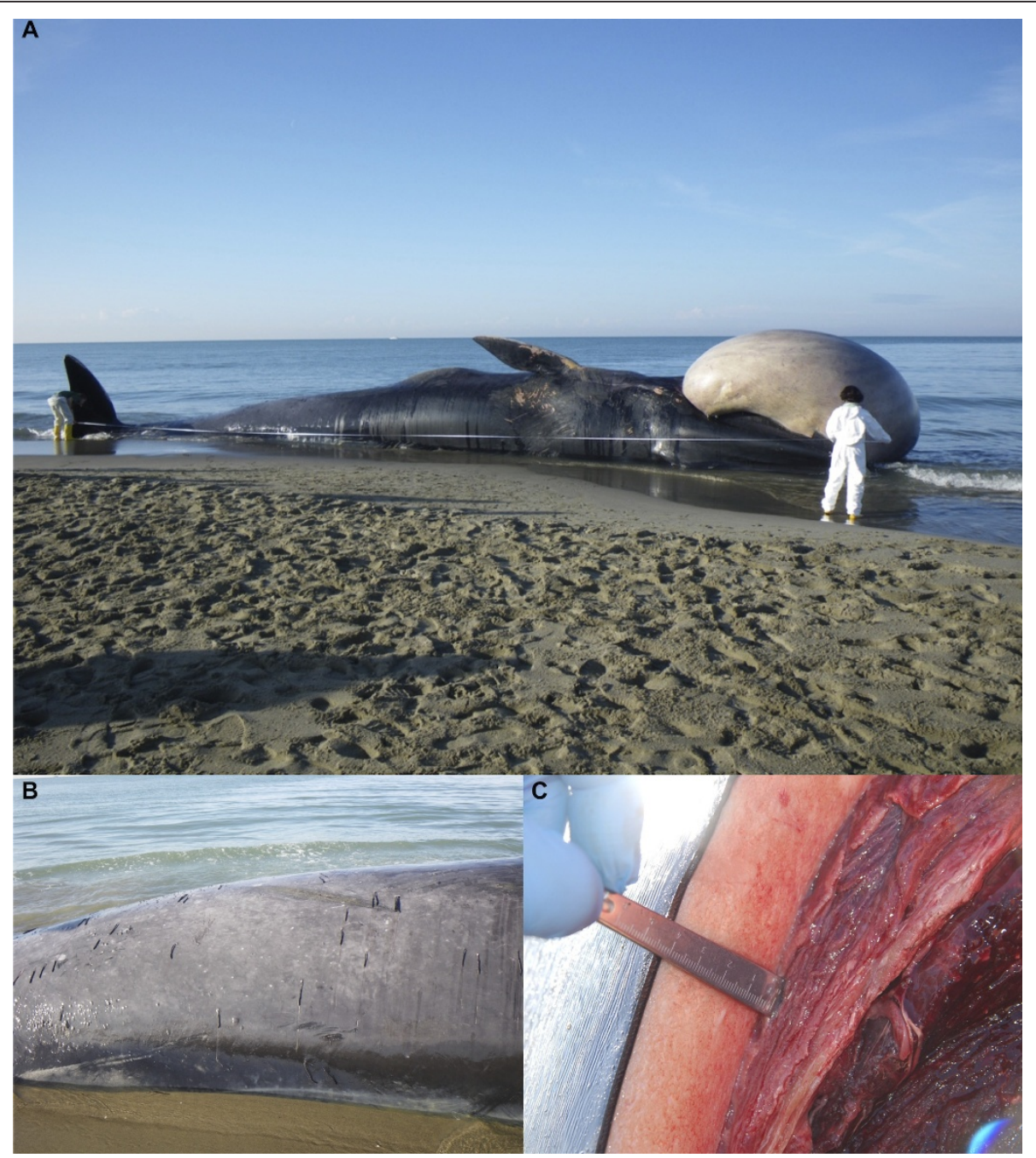

Figure 1 Steps of the necropsy carried out on the stranded whale. Biometrical measurements were taken before starting post-mortem analyses (A). A severe cutaneous parasitic infestation by Pennella spp. (B) was evident during external examination and a poor body condition was assessed due to a reduction of the blubber layer (C).

Masson's trichrome, Gram). Microbiological, immunohistochemical and biomolecular investigations for the main cetacean pathogens (Morbillivirus, Herpesvirus, Brucella spp., and T. gondii) were also performed on all major organs. Specifically, we utilized RT-PCR techniques targeting a highly conserved Morbillivirus nucleoprotein gene sequence (amplicon size $287 \mathrm{bp}$ ) and PCR techniques amplifying a conserved region of the nssrRNA gene (approximately $300 \mathrm{bp}$ in size) of coccidian parasites (Apicomplexa). Furthermore, immunohistochemical labeling for Morbillivirus and T. gondii antigens was attempted on molecularly positive tissues [7].

The whale showed quite an advanced post-mortem decomposition (code 3) and a compromised nutritional status (Figure 1A), as documented by the reduced mean thickness $(4.2 \mathrm{~cm})$ of the blubber layer (Figure 1C) and by the absence of food in the gastric chambers. A severe parasitic infestation by Pennella spp. diffusely involved the animal's skin (Figure 1B). Opening of major body cavities showed a mild bilateral hydronephrosis, secondary to partial obstruction of ureters and pelvis by calcified parasitic remains (presumably, Crassicauda spp.), which were macroscopically assessed. Other relevant pathological findings included massive hepatic and splenic enlargement, congestive mesenteric lymphadenopathy, and mild diffuse fibrinous peritonitis. Microscopic examination of the organs also showed erythrophagocytosis in the spleen. Biomolecular investigations yielded positive results for DMV-specific genome sequences from the whale's lung, spleen, and liver (GenBank accession nr: EF469546.1), with $T$. gondii genomic sequences being simultaneously detected in renal, cardiac and 


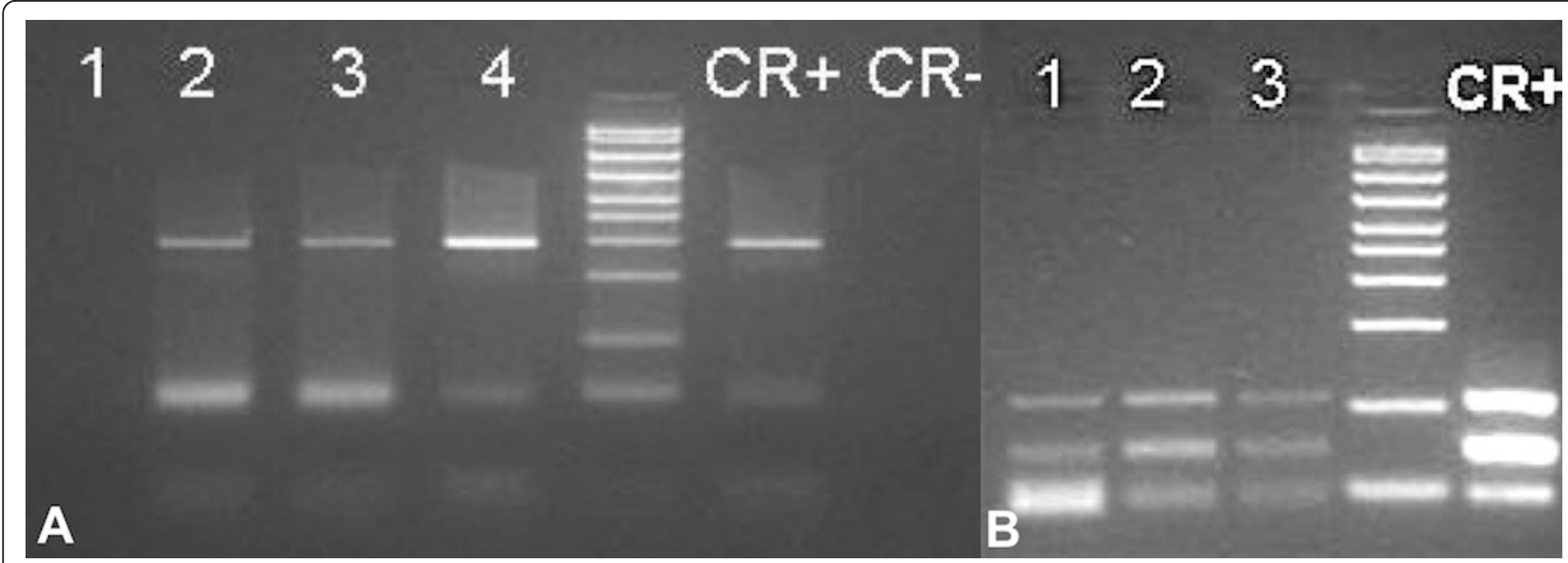

Figure 2 Molecular analyses yielded a positive result for Morbillivirus-specific genome sequences. RT-PCR targeting Morbillivirus nucleoprotein ( $N$ ) gene gave positive results from the whale's spleen (lane 2), liver (lane 3), and lung (lane 4), while the heart was negative (lane 1); positive and negative controls ( $C+$ and $C$-, respectively) are also shown in figure $A$ along with the DNA ladder marker. Each result was confirmed by means of both sequence and RFLP: the latter is shown in figure B with the positive reaction for spleen (lane 1), liver (lane 2), and lung (lane 3). Immunohistochemistry (IHC) using a commercially available mouse monoclonal antibody (MoAb) solution (1:500) against canine distemper virus (CDV) nucleoprotein antigen (VMRD Inc), which recognizes the same epitope from different members of the Morbillivirus genus (including DMV) was negative, possibly due to bad tissue preservation.

musculoskeletal tissues, as well as in mesenteric lymph nodes (GenBank accession nr: AY663792) (Figures 2 and 3). Specificity confirmation of each result was assessed by means of both sequence and RFLP analysis for DMV and sequence analysis for T. gondii, respectively (Figure 2). Rare and isolated T. gondii cysts could be also immunohistochemically labeled in kidney and heart (Figure 3), with immunohistochemical staining for morbilliviral antigen being negative in all examined tissues. Finally, ecotoxicological investigations detected high organochlorine $(\mathrm{OC})$ pollutant levels in blubber (total PCBs: $21269.16 \mathrm{ng} / \mathrm{g}$ lipidic weight; total DDTs: $23720.94 \mathrm{ng} / \mathrm{g}$ lwt).

The present study represents the third report of Morbillivirus infection in a fin whale worldwide [2], thus confirming the susceptibility of Mysticetes to this virus, as also suggested by the seropositivity previously described in an Icelandic fin whales [3] and in a minke whale from the Mediterranean Sea [4]. Furthermore, this report is a further proof of the diffusion of morbilliviral infection among cetaceans of the Mediterranean Sea basin, namely pilot whales (Globicephala melas), striped dolphins, and bottlenose dolphins (Tursiops truncatus) along Spanish, French and Italian coastlines [10-13]. During the dramatic morbilliviral epidemic in the Mediterranean Sea from 1990 to 1992, coinfection with T. gondii, an opportunistic pathogen for cetaceans, was reported in striped dolphins [14]. In Mysticetes, the only previous report of infection is limited to seropositivity against $T$. gondii in a humpback whale (Megaptera novaeangliae) from the Atlantic Ocean [15]. To the best of our knowledge, this is the first DMV and T. gondii coinfection described in a baleen whale. In our fin whale specimen, the molecular identification of $T$. gondii supports the hypothesis of a severe impairment of the immune system, likely induced by the coexisting morbilliviral infection [2]. In contrast to what established during the investigations on the 2006-2008 morbilliviral epidemic in the Mediterranean Sea [16], the consistent body concentrations of $\mathrm{OC}$ contaminants measured in the fin whale under study, which were higher than those found in free-ranging animals $[17,18]$, were considered as a likely worsening factor, accompanied by concurrent kidney dysfunction and prolonged fasting, similarly to what occurred during the 1990-1992 epidemic [2]. Furthermore, the absence of evident pathological changes related to $T$. gondii in the heart and in the mesenteric lymph nodes, which appeared non-compromised, suggests an acute protozoan infection.

The transmission pathways through which cetaceans acquire $T$. gondii infection are currently unknown, although $T$. gondii oocysts have been recently demonstrated in run-off waters, shellfish, and filter-feeding fish $[5,19,20]$; furthermore, oocysts may survive in sea water and remain infective for up to 6 months [21]. No data are available on the route of transmission of $T$. gondii infection in the fin whale described here; however, the animal may have acquired the pathogen while swimming in shallow waters in the days immediately preceding the stranding, with such possibility highlighting the risk of toxoplasmosis for immunodepressed mammals in the marine environment. 


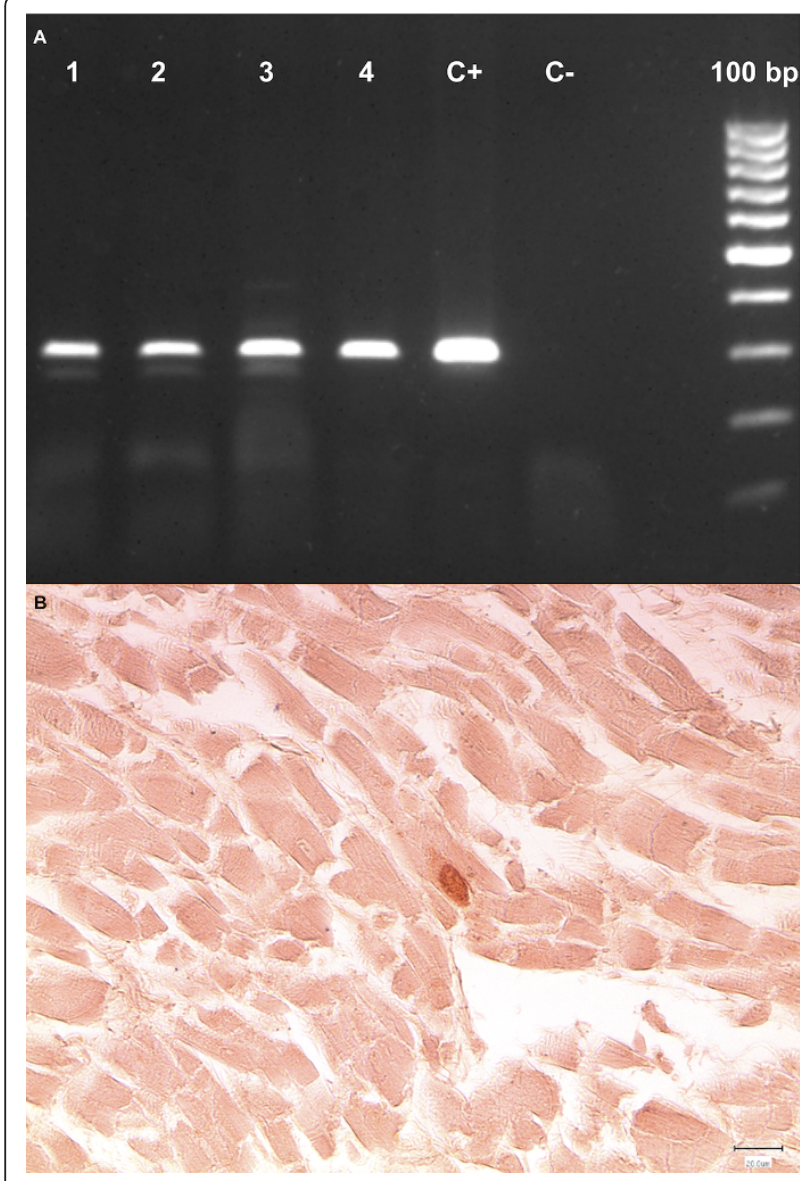

Figure 3 Molecular and immunohistochemical studies confirmed the presence of $T$. gondii in the whale's tissues. PCR techniques amplifying a conserved region of coccidian parasites yielded positive results for T. gondii in the heart (lane 1), skeletal muscle (lane 2), mesenteric lymph node (lane 3), and kidney (lane 4); positive and negative controls ( $C+$ and $C$-, respectively) are also shown in figure $\mathrm{A}$ along with the DNA ladder marker. $\mathrm{HC}$ by means of a commercially available goat polyclonal anti-T. gondii antiserum solution (1:1000; VMRD Inc, Pullman, WA) showed rare T. gondii cysts embedded into both the myocardial $(B ; 400 \times$, bar $=20 \mu \mathrm{m})$ and the renal tissue.

\section{Conclusion}

Considering the features and the size of the Mediterranean fin whales' population [22,23], DMV and T. gondii, especially when occurring in association to each other and under the influence of anthropogenic activities on cetacean populations living in Mediterranean waters [24], may pose a serious threat for this already endangered species.

\section{Author details}

${ }^{1}$ Department of Comparative Biomedicine and Food Science, University of Padova, AGRIPOLIS - Viale dell'Università, 16, 35020 Legnaro, (PD), Italy. ${ }^{2}$ Department of Animal Medicine, Production and Health, University of Padova, viale dell'Università 16, 35020 Legnaro, (PD), Italy. ${ }^{3}$ Istituto
Zooprofilattico Sperimentale del Piemonte Liguria e Valle d'Aosta, via Bologna 148, 10154 Torino, Italy. ${ }^{4}$ Department of Environmental Science, University of Siena "G. Sarfatti", via P.A. Mattioli 4, 53100 Siena, Italy. ${ }^{5}$ Department of Comparative Biomedical Sciences, University of Teramo, piazza Aldo Moro 45, 64100 Teramo, Italy.

\section{Authors' contributions}

Necropsy and microscopic examinations were performed by SM along with LM, FM and WM; FM and LS analyzed tissue for parasites; MG, GDG and CC studied viral infections by PCR as well as by immunohistochemistry; LM carried out toxicological examination on sampled tissues and coordinated photo-ID matching; the manuscript was prepared and critically discussed by SM, GDG and CC with the contribution of all the remaining authors. All authors read and approved the final manuscript.

\section{Competing interests}

The authors declare that they have no competing interests.

Received: 26 September 2011 Accepted: 7 March 2012 Published: 7 March 2012

\section{References}

1. Di Guardo G, Mazzariol S, Fernandez A: Biologically threatened dolphins and whales. Environ Microbiol 2011, 13:2833-2834.

2. Jauniaux T, Charlier G, Desmecht M, Haelters J, Jacques T, Losson B, Van Gompel J, Tavernier J, Coignoul F: Pathological Findings in Two Fin Whales (Balaenoptera physalus) with Evidence of Morbillivirus Infection. J Comp Pathol 2000, 123:198-201.

3. Di Guardo G, Agrimi U, Morelli L, Cardeti G, Terracciano G, Kennedy S: Post mortem investigations on cetaceans found stranded on the coasts of Italy between 1990 and 1993. Vet Rec 1995, 136:439-442.

4. Blixenkrone-Møller M, Bolt G, Jensen TD, Harder T, Svansson V: Comparative analysis of the attachment protein gene $(\mathrm{H})$ of dolphin morbillivirus. Virus Res 1996, 40:47-55

5. Van Bressem MF, Raga JA, Di Guardo G, Jepson PD, Duignan PJ, Siebert U, Barrett T, Santos MC, Moreno IB, Siciliano S, Aguilar A, Van Waerebeek K: Emerging infectious diseases in cetaceans worldwide and the possible role of environmental stressor. Dis Aquat Org 2009, 86:143-145.

6. Mazzariol S, Di Guardo G, Petrella A, Marsili L, Fossi CM, Leonzio C, Zizzo N, Vizzini S, Gaspari S, Pavan G, Podestà M, Garibaldi F, Ferrante M, Copat C, Traversa D, Marcer F, Airoldi S, Frantzis A, Quirós Yde B, Cozzi B, Fernández A: Sometimes sperm whales (Physeter macrocephalus) cannot find their way back to the high seas: a multidisciplinary study on a mass stranding. PLoS One 2011, 6:e19417.

7. Di Guardo G, Proietto U, Di Francesco CE, Marsilio F, Zaccaroni A, Scaravelli D, Mignone W, Garibaldi F, Kennedy S, Forster F, lulini B, Bozzetta $E$, Casalone C: Cerebral toxoplasmosis in striped dolphins (Stenella coeruleoalba) stranded along the Ligurian Sea coast of Italy. Vet Pathol 2010, 47:245-253.

8. McLellan W, Rommel S, Moore M, Pabst DA: Right whale necropsy protocol. Contract report to NOAA Fisheries 2004.

9. Pugliares KR, Bogomolni A, Touhey KM, Herzig SM, Harry CT, Moore MJ: Marine Mammal Necropsy: An introductory guide for stranding responders and field biologists. Technical Report WHOI-2007-06 2007.

10. Fernández A, Esperón F, Herraéz $P$, de Los Monteros AE, Clavel C, Bernabé A, Sánchez-Vizcaino JM, Verborgh P, DeStephanis R, Toledano F, Bayón A: Morbillivirus and pilot whale deaths, Mediterranean Sea. Emerg Infect Dis 2008, 14:792-794

11. Raga JA, Banyard A, Domingo M, Corteyn M, Van Bressem MF, Fernández M, Aznar FJ, Barrett T: Dolphin morbillivirus epizootic resurgence, Mediterranean Sea. Emerg Infect Dis 2008, 14:471-473.

12. Keck N, Kwialek O, Dhermain F, Dupraz F, Boulel H, Danes C, Laprie C, Perrin A, Godenir J, Micout L, Libeau G: Resurgence of Morbillivirus infection in Mediterranean dolphins off the French coast. Vet Rec 2010, 166:654-655

13. Di Guardo G, Cocumelli C, Scholl F, Di Francesco CE, Speranza R, Pennelli M, Eleni C: Morbilliviral encephalitis in a striped dolphin (Stenella coeruleoalba) calf from Italy. Dis Aquat Organ 2011, 95:247-251.

14. Domingo M, Visa J, Pumarola M, Marco AJ, Ferrer L, Rabanal R, Kennedy S: Pathologic and immunocytochemical studies of morbillivirus infection in striped dolphins (Stenella coeruleoalba). Vet Pathol 1992, 29:1-10. 
15. Forman D, West N, Francis J, Guy E: The sero-prevalence of Toxoplasma gondii in British marine mammals. Mem I Oswaldo Cruz 2009, 104:296-298.

16. Castrillon J, Gomez-Campos E, Aguilar A, Berdié L, Borrell A: PCB and DDT levels do not appear to have enhanced the mortality of striped dolphins (Stenella coeruleoalba) in the 2007 Mediterranean epizootic. Chemosphere 2010, 81:459-463.

17. Marsili L, Focardi S: Organochlorine levels in subcutaneous blubber biopsies of fin whales (Balaenoptera physalus) and striped dolphins (Stenella coeruleoalba) from the Mediterranean Sea. Environ Pollut 1996, 91:1-9.

18. Fossi MC, Marsili L, Neri G, Natoli A, Politi E, Panigada S: The use of a nonlethal tool for evaluating toxicological hazard of organochlorine contaminants in Mediterranean cetaceans: new data 10 years after the first paper published in MPB. Mar Pollut Bull 2003, 46:972-982.

19. Massie GN, Ware MW, Villegas EN, Black MW: Uptake and transmission of Toxoplasma gondii oocysts by migratory, filter-feeding fish. Vet Parasitol 2010, 169:296-303.

20. Putignani L, Mancinelli L, Del Chierico F, Menichella D, Adlerstein D, Angelici MC, Marangi M, Berrilli F, Caffara M, di Regalbono DA, Giangaspero A: Investigation of Toxoplasma gondii presence in farmed shellfish by nested-PCR and real-time PCR fluorescent amplicon generation assay (FLAG). Exp Parasitol 2011, 127:409-417.

21. Lindsay DS, Dubey JP: Long-term survival of Toxoplasma gondii sporulated oocysts in seawater. J Parasitol 2009, 95:1019-1020.

22. Notarbartolo di Sciara G, Zanardelli M, Jahoda M, Panigada S, Airoldi S: The Fin whale Balaenoptera physalus (L. 1758) in the Mediterranean Sea. Mammal Rev 2003, 33:105-150

23. Panigada S, Lauriano G, Burt L, Pierantonio N, Donovan G: Monitoring winter and summer abundance of cetaceans in the Pelagos Sanctuary (northwestern Mediterranean Sea) through aerial surveys. PLoS One 2011, 6:e22878.

24. Panigada S, Pesante G, Zanardelli M, Capoulade F, Gannier A, Weinrich MT: Mediterranean fin whales at risk from fatal ship strikes. Mar Pollut Bull 2006, 52:1287-129.

doi:10.1186/1746-6148-8-20

Cite this article as: Mazzariol et al:: Dolphin Morbillivirus and Toxoplasma gondii coinfection in a Mediterranean fin whale (Balaenoptera physalus). BMC Veterinary Research 2012 8:20.

\section{Submit your next manuscript to BioMed Central and take full advantage of:}

- Convenient online submission

- Thorough peer review

- No space constraints or color figure charges

- Immediate publication on acceptance

- Inclusion in PubMed, CAS, Scopus and Google Scholar

- Research which is freely available for redistribution

Submit your manuscript at www.biomedcentral.com/submit 